\title{
Basin-scale heterogeneity in Antarctic precipitation and its impact on surface mass variability
}

\author{
Jeremy Fyke ${ }^{1}$, Jan T. M. Lenaerts ${ }^{2,3}$, and Hailong Wang ${ }^{4}$ \\ ${ }^{1}$ Los Alamos National Laboratory, Los Alamos, New Mexico, USA \\ ${ }^{2}$ Department of Atmospheric and Oceanic Sciences, University of Colorado, Boulder, Colorado, USA \\ ${ }^{3}$ Institute for Marine and Atmospheric Research, Utrecht University, Utrecht, the Netherlands \\ ${ }^{4}$ Pacific Northwest National Laboratory, Richland, Washington, USA
}

Correspondence to: Jeremy Fyke (fyke@lanl.gov)

Received: 6 June 2017 - Discussion started: 23 June 2017

Revised: 28 September 2017 - Accepted: 5 October 2017 - Published: 15 November 2017

\begin{abstract}
Annually averaged precipitation in the form of snow, the dominant term of the Antarctic Ice Sheet surface mass balance, displays large spatial and temporal variability. Here we present an analysis of spatial patterns of regional Antarctic precipitation variability and their impact on integrated Antarctic surface mass balance variability simulated as part of a preindustrial 1800-year global, fully coupled Community Earth System Model simulation. Correlation and composite analyses based on this output allow for a robust exploration of Antarctic precipitation variability. We identify statistically significant relationships between precipitation patterns across Antarctica that are corroborated by climate reanalyses, regional modeling and ice core records. These patterns are driven by variability in large-scale atmospheric moisture transport, which itself is characterized by decadalto centennial-scale oscillations around the long-term mean. We suggest that this heterogeneity in Antarctic precipitation variability has a dampening effect on overall Antarctic surface mass balance variability, with implications for regulation of Antarctic-sourced sea level variability, detection of an emergent anthropogenic signal in Antarctic mass trends and identification of Antarctic mass loss accelerations.
\end{abstract}

\section{Introduction}

Precipitation of snow is the means by which the Antarctic Ice Sheet (AIS), currently the largest contiguous ice complex on the planet, gains mass. Over time, this accumulation has resulted in the sequestration of $57 \mathrm{~m}$ of eustatic sea level equivalent as AIS ice (Fretwell et al., 2013). As a result of the large area of this capacitor of freshwater, natural variability in AIS-integrated precipitation has a leading impact on AIS mass trends, which in turn influence global mean sea level (GMSL) variability.

AIS-integrated precipitation variability combines the effect of regional precipitation variability signals. Previous studies have leveraged Gravity Recovery and Climate Experiment (GRACE) output, satellite altimetry and/or regional modeling to highlight strongly heterogeneous spatial patterns of temporal variability in surface mass balance (SMB; e.g., Mémin et al., 2015; Martín-Espanõl et al., 2016; Shepherd et al., 2012; Boening et al., 2012). Complementing these remotely sensed observations, longer time series of SMB from ice cores (e.g., Frezzotti et al., 2013; Thomas et al., 2017, and references therein) also suggest the presence of heterogeneous regional patterns of precipitation variability. Historical climate reanalysis (Dee et al., 2011) as well as regional models driven by this reanalysis (e.g., Van Wessem et al., 2014) further confirm the presence of spatial heterogeneity in recent historical Antarctic precipitation variability signals (Genthon et al., 2003; Genthon and Cosme, 2003; Wang et al., 2016).

These analyses provide critical insight into historical drivers of ice sheet mass balance variability and hint at a potentially strong role for heterogeneous patterns of precipitation variability in regulating AIS-integrated mass variability. They are also important in understanding future change, during which regional variability will be superim- 
posed on by a strong secular trend towards greater precipitation (Palerme et al., 2016; Frieler et al., 2015; Previdi and Polvani, 2016; Lenaerts et al., 2016) and increased lowelevation surface melting (Fyke et al., 2010; Trusel et al., 2015). However, they are characteristically hampered by either short time series length, sparse point data, observational uncertainty, a mixture of forced and natural variability signals or a combination of all of these.

Analysis of global climate model output provides a potential pathway around these difficulties. In particular, preindustrial climate model control simulations - long quasiequilibrium simulations in which no time-varying external forcing is applied (e.g., Eyring et al., 2016) - provide spatially complete, temporally extensive representations of natural climate variability that are uncontaminated by external forcing changes. Motivated by the potential for climate model output to provide robust dynamical insight into drivers of spatially heterogeneous Antarctic precipitation variability, here we use the Community Earth System Model (Hurrell et al., 2013) to explore spatial patterns in Antarctic precipitation variability. The study is presented as follows: in Sect. 2 we describe the model, simulation and analysis methods we adopt to explore Antarctic precipitation variability. In Sect. 3 we detail the findings of our analyses, which are further interpreted in Sects. 4 and 5.

\section{Methods}

We explore AIS basin-scale precipitation ${ }^{1}$ variability and its link to broader climate patterns using output from the Community Earth System Model (CESM, version 1). CESM is a comprehensive coupled Earth system model that is used for a diverse range of applications, including recent explorations of Southern Hemisphere and Antarctic climate (e.g., Holland et al., 2016; Lenaerts et al., 2016). The particular CESM simulation we focus our analysis on is a $\sim 1^{\circ}$ resolution preindustrial control simulation of the CESM Large Ensemble experiment (CESM LE hereafter; Kay et al., 2015). Output from AD 400 to 2200 of this fully coupled simulation provides a robustly equilibrated (and thus statistically stationary) representation of global climate system dynamics that is uncontaminated with anthropogenic or other external climate forcings, and of sufficient length (1800 years) to support robust variability analysis. This approach to assessing Antarctic variability provides important insights that are difficult to obtain using reanalysis products from the relatively short/non-stationary recent historical period. Our methodological approach is similar to other investigations of

\footnotetext{
${ }^{1}$ In the following, we consider "precipitation" to be practically synonymous with "snowfall" since rain accounts for approximately $0.1 \%$ of total precipitation over Antarctica in the simulation described here. We define "accumulation" as the net surface mass balance, which for much of Antarctica equals precipitation minus sublimation in the absence of significant surface meltwater runoff.
}

unforced Southern Hemisphere climate variability that use output from climate model control simulations forced with either constant preindustrial or constant present-day conditions (e.g., Genthon and Cosme, 2003; Santoso et al., 2006; Holland et al., 2005; Previdi and Polvani, 2016).

We represent regional Antarctic precipitation heterogeneity by disaggregating the AIS into individual AIS drainage basins (Zwally et al., 2012; Fig. 1). Ice shelves are included in this basin disaggregation. This approach is adopted because each basin represents a distinct dynamical integrator of regional climate signals, making basin-scale analysis a practical and glaciologically tractable method for linking climate-driven precipitation variability to regional ice dynamical changes. Previous Antarctic principal component analysis-based precipitation studies have identified major benefits associated with use of limited Antarctic (Genthon et al., 2003) and West Antarctic Ice Sheet (WAIS; Genthon and Cosme, 2003) domains. Specifically, these domains allow for isolation of important sector-relevant variability patterns that can be obscured within of larger-scale hemispheric or global analyses. By further extending the "local analysis" methodology to individual ice sheet basins, we provide even greater control on identification of regionally critical variability drivers, which in larger-scale approaches can overlap and also be obscured by more dominant spatial modes of variability (Genthon et al., 2003).

At the basin scale, we focus primarily on drivers of variability in annually averaged, spatially integrated precipitation rates (units of $\mathrm{Gt} \mathrm{yr}^{-1}$ ) because of the importance of this measure for mass balance and dynamics, combined with the relative insensitivity of long-term AIS ice sheet dynamics to higher-frequency variability (e.g., related to the seasonal cycle and/or individual storm events, which nonetheless are important in summing to the net annual signal). We apply several analysis tools to quantify simulated basinscale variability, compare inter-basin variability relationships, and link basin-scale variability to broader patterns of climate variability. We first perform correlation analysis between basin-specific annually averaged precipitation time series to identify inter-basin variability relationships. In addition, for each basin, we use composite climatologies based on basin-scale annually averaged precipitation to construct paired monthly resolved characteristic climate states associated with high/low basin precipitation years. This allows for examination of the relationships between basin-resolved precipitation time series and broader modes of climate variability. To verify that the patterns of variability identified in CESM model output are robust, we repeated subsets of our analysis on output from a $27 \mathrm{~km}$ resolution RACMO2.3 regional atmosphere/ice sheet surface model simulation spanning the 1979-2015 period. RACMO2.3 has been extensively validated over Antarctica, thus providing an important benchmark of CESM performance (Lenaerts et al., 2016). Finally, we also compare the CESM results against estimates of accumulation variability derived from ice core records, and 

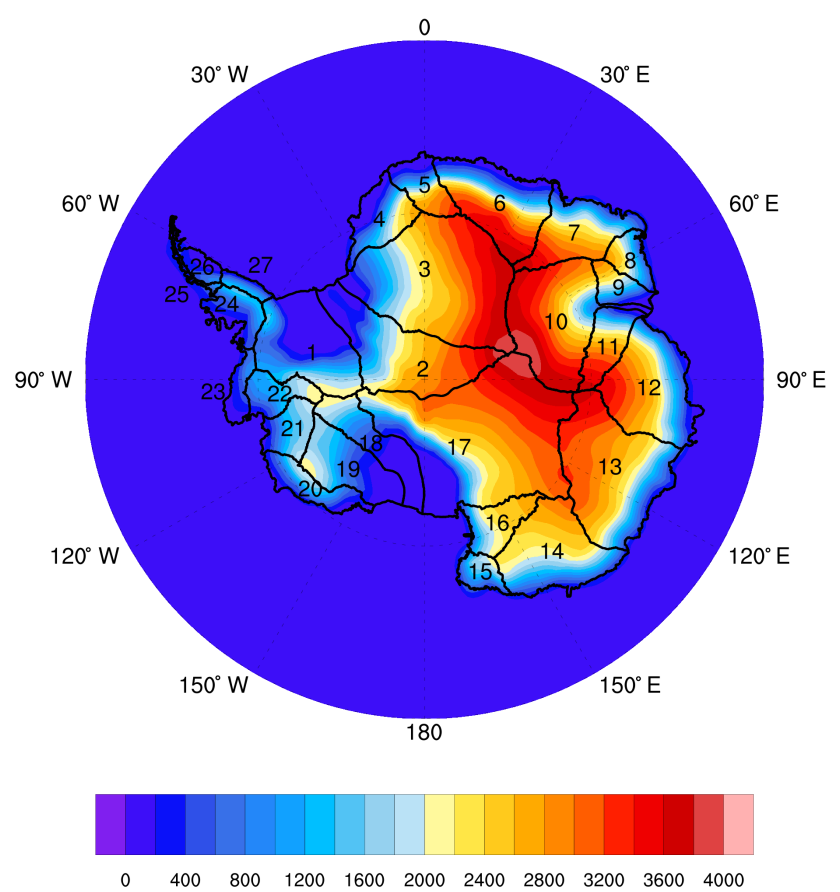

Figure 1. Colors: Antarctic Ice Sheet surface topography (meters). Outlines: numbered Antarctic Ice Sheet basins (Zwally et al., 2012).

identify the impact of low-frequency variability on Antarctic precipitation patterns by performing time-dependent basinscale correlation analysis.

\section{Results}

\subsection{Simulated preindustrial Antarctic precipitation variability}

CESM1.1-simulated AIS precipitation over the historical period has been analyzed in detail in Lenaerts et al. (2016). Given similar model provenance, the spatial pattern in the CESM LE control simulation is similar to that validated by Lenaerts et al. (2016), with lowest values in the dry interior and high values around the coast, particularly along the Amundsen Sea coastline and the Antarctic Peninsula (Fig. 2a). The model produces a climatological AIS-wide integrated precipitation of $2168 \mathrm{Gtyr}^{-1}$, of which $\sim 0.1 \%$ falls as liquid. This value is lower than recent historical mean CESM/RACMO2.3 precipitation assessed in Lenaerts et al. (2016) and (Van Wessem et al., 2014; 2428/2829 $\mathrm{Gt} \mathrm{yr}^{-1}$ ), due to the significant positive trend in historical CESMsimulated integrated Antarctic precipitation combined with an overall negative CESM precipitation bias.

The spatial pattern of interannual variability in modeled precipitation, measured as the standard deviation of the annual average, largely mirrors the spatial pattern of climatological precipitation magnitude: where the magni- tude is high, so too is the variability (Fig. 2b). Precipitation variability is highest around the Antarctic coast, and reaches maximum values between Marie Byrd Land and the Antarctic Peninsula. In contrast, minimum variability occurs over the East Antarctic plateau. The standard deviation of AIS-integrated annually averaged precipitation variability is $98 \mathrm{Gt} \mathrm{yr}^{-1}$, which is lower than recent historical variability in both CESM and RACMO2.3 (122/135 $\left.\mathrm{Gt} \mathrm{yr}^{-1}\right)$, consistent with lower overall climatological precipitation. Ranking of basin-scale precipitation contributions to overall variability highlights the leading influences of basin 20 (Marie Byrd Land of West Antarctica) and, secondarily, basins 12-14 (Adelie Land to Wilhelm II Land of East Antarctica) in regulating overall variability due to very high basin-integrated precipitation rates despite relatively small size (for the former) and large extent despite relatively low precipitation rates (for the latter).

Relative variability in Antarctic precipitation is assessed via the coefficient of variation (CV), which is calculated as the standard deviation divided by the mean (e.g., Turner et al., 1999, Fig. 12). The spatial pattern of CESM-simulated CV (Fig. 2c) differs notably from the spatial patterns of both mean precipitation and precipitation variability, indicating the influence of both in regulating relative variability. Low site-specific CV values arise over the Antarctic Peninsula (AP), the coastal WAIS and along major AIS ice divides. A similar pattern is also apparent in RACMO2.3 output (not shown). High mean precipitation drives low $\mathrm{CV}$ over the AP and coastal WAIS, while low CV along ice divides is likely related to low variability at these locations, perhaps associated with the large influence of steady background clear-sky precipitation (Bromwich, 1988). Conversely, relatively high variability combined with relatively low mean precipitation conspire to generate highest $\mathrm{CV}$ values over the Ross and Amery ice shelves, Victoria Land, George V Land, Dronning Maud Land and the eastern Ronne-Filchner Ice Shelf. A similar pattern is also apparent in RACMO2.3 (van de Berg et al., 2006) and also reflected in earlier estimates of Antarctic precipitation variability (Turner et al., 1999).

AIS-integrated CV calculated using the mean and standard deviation of AIS-integrated precipitation is 0.04 . This value is very similar to the recent historical AIS-integrated CV generated by both CESM and RACMO2.3 (0.06/0.04). However, it is very low relative to CESM-simulated CV values at individual grid points on the model domain (average of 0.2). This large difference between AIS-integrated and local values also holds when comparing AIS-integrated CV to $\mathrm{CV}$ calculated at the basin scale, which is also higher as evidenced qualitatively by the wider distributions of normalized basin-scale precipitation relative to the AIS-wide integrated distribution (Fig. 2d) and quantitatively by a mean $\mathrm{CV}$ of 0.17 across basins - more than 4 times higher than the icesheet-integrated value. This much larger basin-averaged CV value relative to the value calculated from the AIS-integrated precipitation time series implies the presence of opposing 

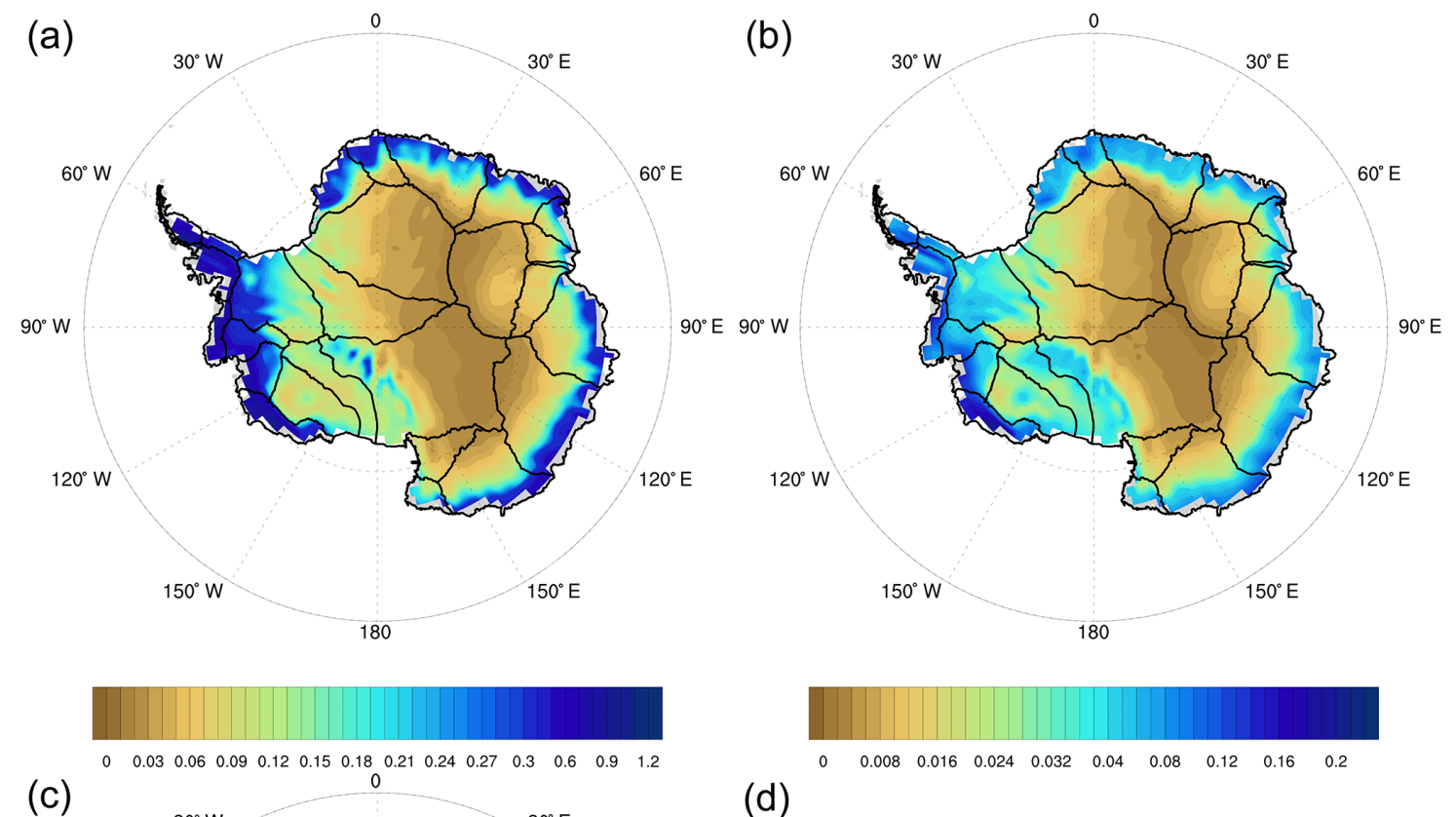

(d)
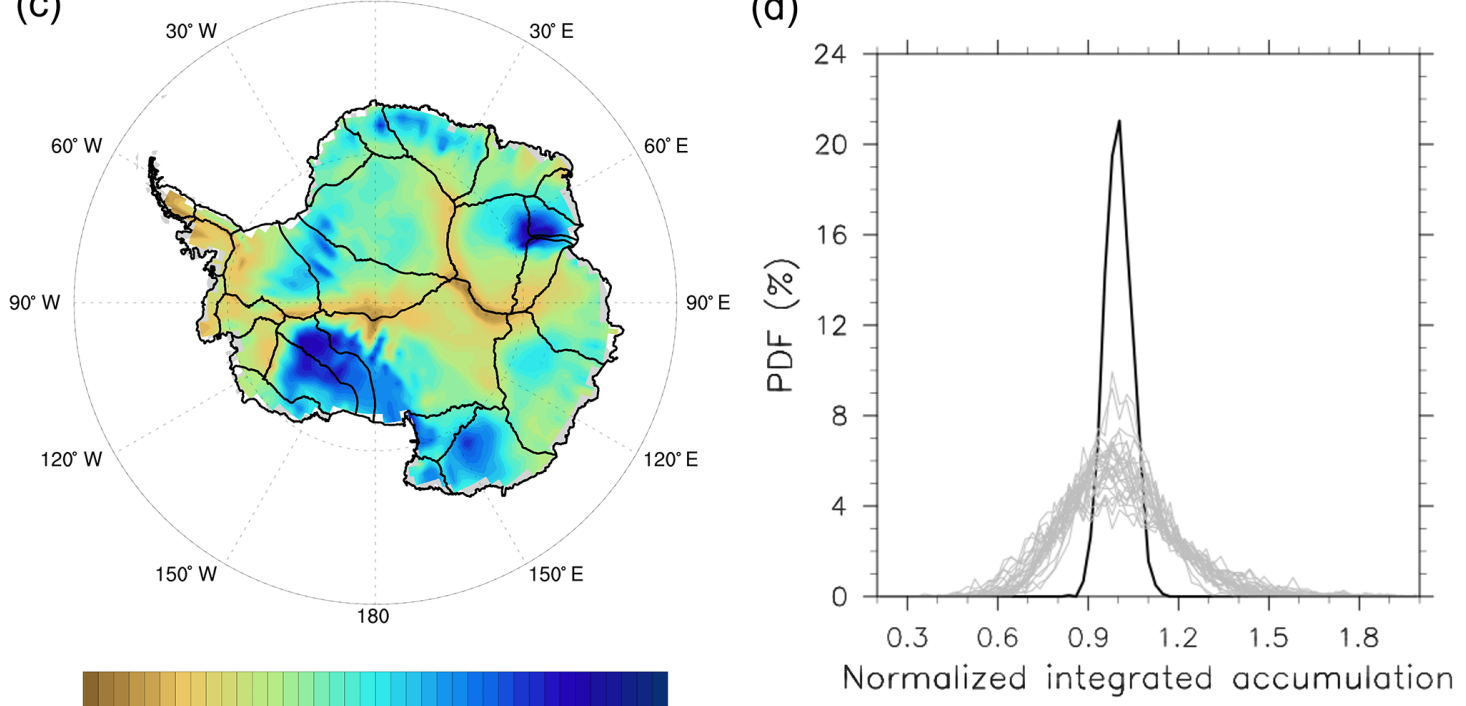

Figure 2. (a) Climatological mean CESM-simulated AIS precipitation ( $\mathrm{m} \mathrm{yr}^{-1}$ w.e.). (b) Climatological AIS standard variability (standard deviation, $\mathrm{m} \mathrm{yr}^{-1}$ w.e.). (c) Coefficient of variation (CV, standard deviation divided by the mean). AIS drainage basins (Zwally et al., 2012) overlaid on panels (a)-(c). Note nonlinear color bars in panels (a)-(b). (d) Normalized distributions of annual average precipitation, over the entire 1800-year simulation. Normalization carried out by dividing each distribution by the mean distribution value. Black line: AIS-wide integrated precipitation distribution. Grey lines: individual drainage basin distributions.

precipitation patterns that dampen the contribution of regionally high regional variability to the AIS-integrated variability signal. It also suggests that the impact of regional AIS precipitation variability is quickly obscured in cases where aggregation to larger spatial scales is employed. On the other hand, the similarity of basin-based and pointwise-based CV averages $(0.17 / 0.2)$ indicates that little information about variability is lost in basin-scale aggregation, supporting our use of basin-scale disaggregation in exploration of the interplay between regional ice sheet variability patterns.

\subsection{Inter-basin countervailing precipitation signals}

To identify the spatial patterns of regional precipitation variability that dampen AIS-wide integrated variability, we examine zero-lag temporal correlations in CESM-simulated time series of annual average integrated precipitation between all drainage basins. Figure 3 a shows the matrix of resulting correlation coefficients, while Fig. 4 shows the spatial distribution of inter-basin precipitation correlations for 
(a)

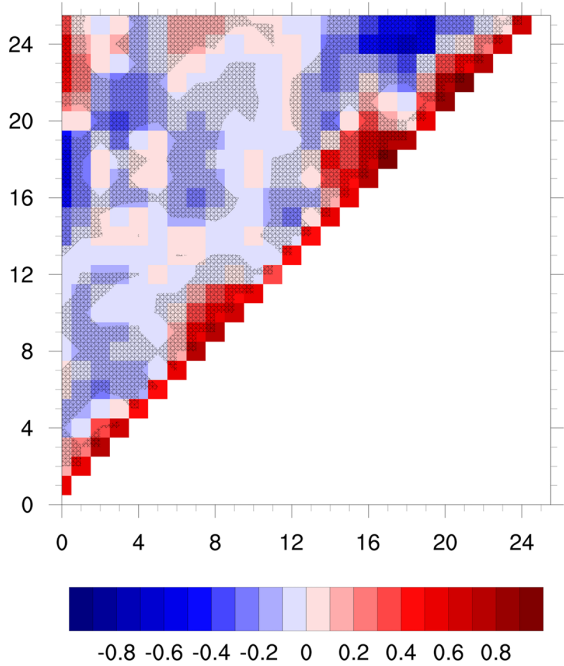

(b)

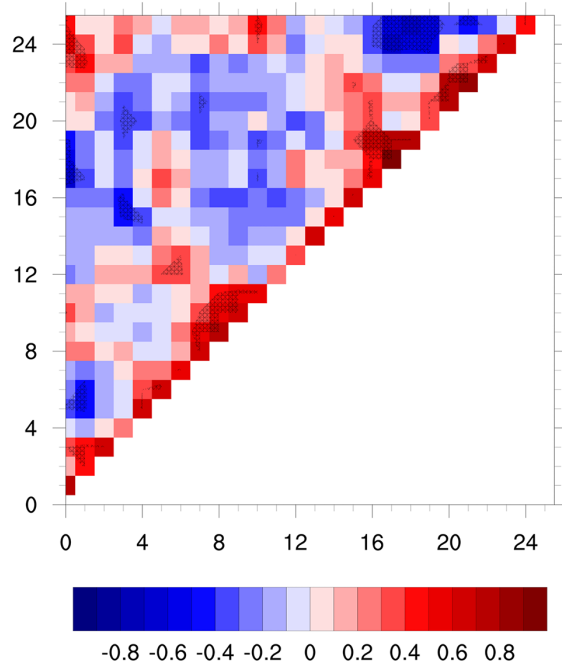

Figure 3. (a) CESM-simulated inter-basin annual integrated precipitation correlation coefficients (colored squares). Horizontal and vertical axes: Antarctic Ice Sheet basin number (Fig. 1). (b) RACMO-simulated inter-basin annual integrated precipitation correlations. Stippling indicates significance at the $95 \%$ level. Main diagonal (correlations of basins with themselves) and duplicate correlations are excluded.

a select set of basins chosen to represent four quadrants of Antarctica (plots for all basins available in the Supplement).

The presence of not only dampening but also actively counteracting basin-specific integrated precipitation signals is demonstrated by the presence of multiple statistically significant $(95 \%$ confidence interval) inter-basin negative correlations with respect to basin-scale integrated precipitation (blue squares in Fig. 3a). On average, while each basin's precipitation variability is significantly positively correlated with 9 other basins (of 11 total average positive correlations per basin), each basin is also significantly anti-correlated with 12 other basins (of 16 total average negative correlations per basin). The presence of significantly anti-correlated inter-basin precipitation variability patterns reflects the fact that high-/low-precipitation years in one basin are synonymous with low/high years in other basins, with directly canceling effects on the AIS-wide integrated variability signal.

The spatial patterns of opposing variability associated with the matrix of correlation coefficients in Fig. 3 are highly basin-specific, indicating that inter-basin correlation patterns depend highly on the basin of interest. Figure $4 \mathrm{a}-\mathrm{d}$ highlight the large diversity of spatial correlation patterns for the same set of ice sheet drainage basins as in Fig. 4. Analogous figures for all basins can be found in the Supplement. Precipitation in basin 2 demonstrates positive correlations with precipitation in nearby basins, mirrored by negative correlations with more remote basins. Conversely, precipitation in basin 7 correlates positively and significantly with precipitation in both neighboring and remote basins, as well as correlating negatively and significantly with a broad and coherent region of the interior. Basin 14 shows only weak positive correlation levels to neighboring basins and, largely, no significant correlation to more distant basins. Finally, the pattern of correlations based on basin 19 shows a prominent correlation dipole, with high/low precipitation in basin 19 and surrounding basins being countered by low/high precipitation in easterly WAIS basins and the AP.

\subsection{Comparison to RACMO2.3 and ice core basin-scale variability}

Are the patterns of countervailing Antarctic precipitation simulated by CESM realistic? We approach this question by first comparing CESM precipitation variability patterns with that of 1979-2015 RACMO2 Antarctic precipitation (Van Wessem et al., 2014). Figure 3b presents the matrix of RACMO2 inter-basin annual precipitation correlations (equivalent to the analogous CESM matrix, Fig. 3a). RACMO2 precipitation time series at each point are linearly detrended prior to aggregation to the basin scale and correlation. As with CESM, RACMO2 simulates the presence of both multiple positive and negative inter-basin correlations, in a similar spatial pattern to inter-basin correlations to CESM $(r=0.82)$. The presence of the latter robustly supports the CESM-based finding of dampening of the ice-sheet-wide precipitation variability by opposing regional variability patterns. While RACMO2 generates higher absolute positive/negative inter-basin correlation magnitudes (average 13/14 per basin), these are less statistically significant correlations than in CESM. This likely arises from the short RACMO2 time series length (37 years) relative to the CESM time series length (1800 years) and highlights the need for sufficient record length when characterizing ice sheet-related internal variability (e.g., Wouters et al., 2013). 


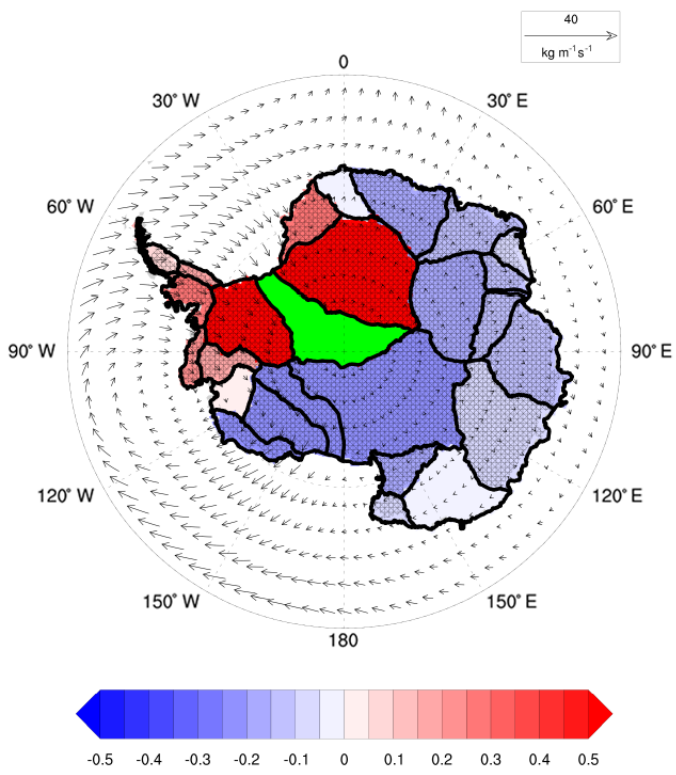

(a)

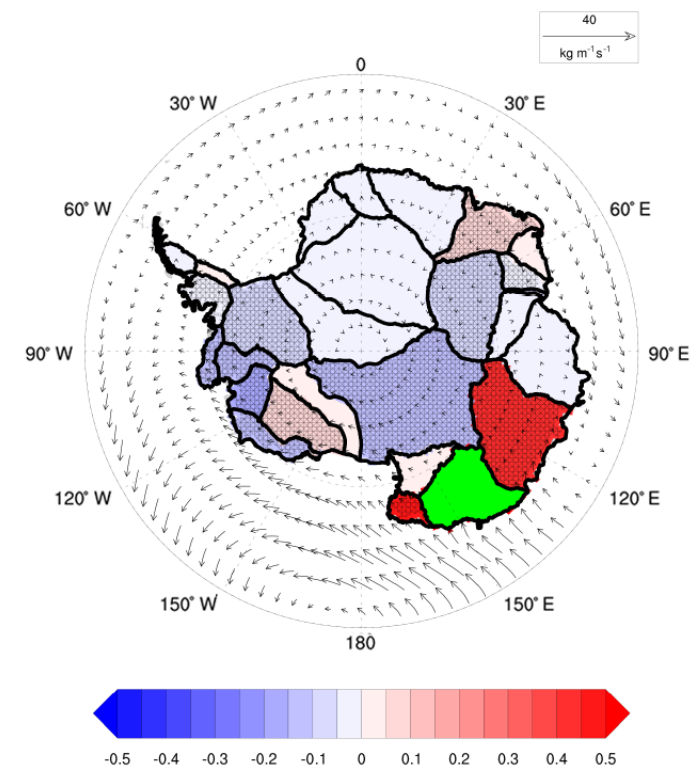

(c)

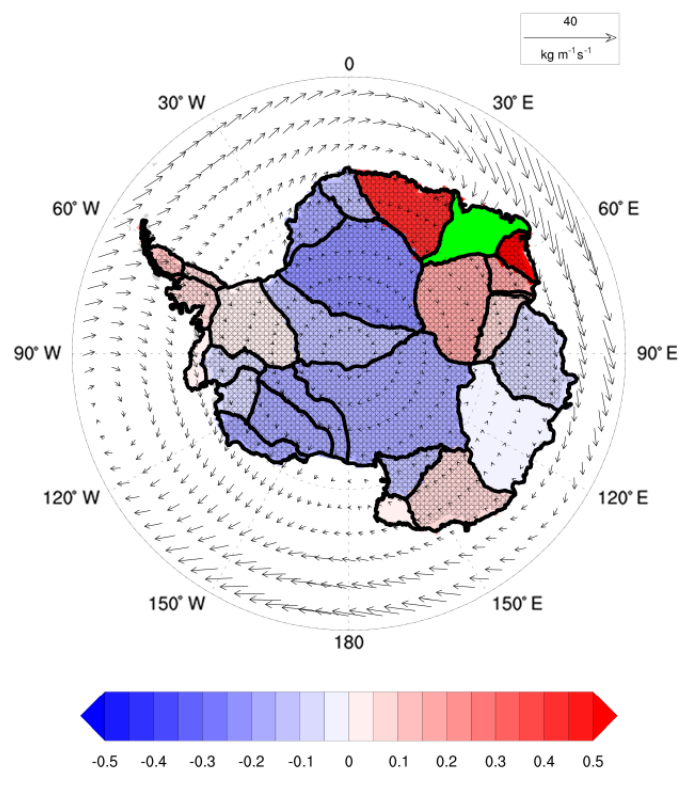

(b)

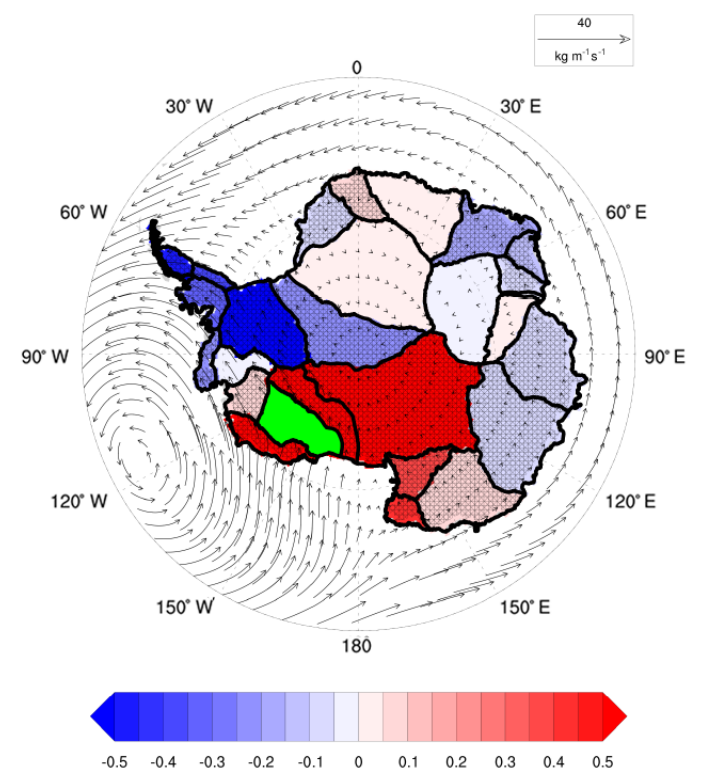

(d)

Figure 4. (a-d) Basin-specific coloring: inter-basin annual integrated precipitation zero-lag correlations for basins 2, 7, 14 and 19 (in green). Stippling represents the presence of inter-basin significance at the $95 \%$ level. Arrows: vector differences between basin-specific composite vertically integrated moisture transport climatologies (high minus low basin-specific integrated precipitation).

Ice and firn cores provide an additional opportunity to directly assess CESM-simulated precipitation variability (Genthon et al., 2005). A recent compilation of AIS ice corederived accumulation variability records was compiled by the Past Global Changes (PAGES) Antarctica 2k working group (Thomas et al., 2017). As part of this work, Thomas et al. (2017) assessed local multi-ice-core composite records in seven sub-regions of Antarctica against other sub-regions 
and RACMO2 and ERA-Interim output. Despite significant noise inherent to annual-scale analysis of Antarctic ice core data, this analysis also suggested the presence of countervailing variability signals, most clearly arising between the Antarctic Peninsula region and the western WAIS and between East and West Antarctica (the latter is also identified by Genthon et al., 2005). The emergence of countervailing variability patterns therefore qualitatively supports similar findings in CESM.

\subsection{Regional controls on opposing Antarctic precipitation variability}

Having established the presence of strong countervailing patterns of Antarctic precipitation variability, we next analyze the underlying climatic drivers. We use basin-scale compositing, where for each ice sheet drainage basin global, monthly resolved composite climatologies associated with low (5th percentile) and high (95th percentile) basin-scale precipitation years are constructed $(n \sim=90$ for each composite). Differencing these basin-based composite climatologies highlights changes in regional climate conditions associated with basin-specific variability.

Because precipitation over Antarctic ice drainage basins is largely dependent on advection of moisture from remote sources as opposed to local recycling (Sodemann and Stohl, 2009; Singh et al., 2016) we first assess basin-specific composite differences in vertically integrated atmospheric zonal and meridional moisture fluxes in the expectation that basinscale variability will be reflected in local atmospheric moisture convergence changes. Indeed, for all basins a consistent change in proximal offshore atmospheric moisture transport anomalies emerges with high-precipitation years co-occurring with positive local onshore moisture transport anomalies and low-precipitation years co-occurring with weaker onshore transport anomalies (Fig. 4 and Supplement). Within each basin, the difference in absolute moisture flux tends to weaken inland, reflecting the dominance of coastal orographically driven precipitation in Antarctica (Favier et al., 2013). Given that basin-integrated precipitation mostly reflects coastal precipitation, the compositing technique preferentially tends towards composite differences that are maximized towards the coast. Moisture flux anomalies are often largest in the local vicinity of the basin for which the compositing was based, identifying local circulation variability as an important final link between remote evaporative source regions and final precipitation location.

The tight relationship between Antarctic basin-scale precipitation and proximal moisture transport variability confirms a leading role for moisture transport in determining local basin precipitation variability (Genthon et al., 2003). At a larger scale, the composite climatologies also confirm spatially coherent moisture transport changes as the causal factor behind inter-basin countervailing precipitation variability. Specifically, for all basins that demonstrate simultane- ous positive/negative precipitation correlations with the basin on which the compositing procedure is based, compositing also identifies corresponding onshore/offshore moisture transport anomalies. As an arbitrary demonstrative example, each basin with precipitation variability that is positively correlated with basin 7 (Fig. 4b) also demonstrates increased onshore moisture transport, with the strength of the correlation tending to increase with increased onshore moisture transport changes. Such basins include several proximal basins, as well as remote basins on the AP and in Victoria Land. The converse relationship holds for anti-correlated basins that tend to occur as a swath of basins across the interior of the East Antarctic Ice Sheet.

Moisture flux anomalies associated with basin-specific precipitation variability, as well as broader patterns of interbasin dampening/countervailing precipitation variability, are tightly linked to composited differences in both $500 \mathrm{hPa}$ geopotential height (Z500, contours in Fig. 5) and sea level pressure (SLP). Stemming from the similarity between SLP and Z500 composite differences $(r=0.91)$ we focus our attention on the relationship of moisture flux changes to Z500 variability, which provides a consistent metric of atmospheric circulation both at sea level and over the elevated ice sheet topography (Genthon et al., 2003). Basin-based precipitation compositing reveals spatially extensive and significant Z500 differences with a transition from positive to negative anomalies - indicating large changes in horizontal pressure gradient anomalies - typically lying in close proximity to the basin from which compositing was based (see, for example, Fig. 5a, b and d). Moisture flux anomalies, which are characteristically maximal close to the composited basin, are consistently $\sim 90^{\circ}$ leftwards of the maximum Z500 gradient. This points to regional geostrophic flow as a main determinant of the moisture transport variability, which in turn drives interannual basin-scale precipitation variability.

However, despite the apparently robust control of atmospheric circulation variability on Antarctic basin-scale precipitation variability, another potential regulator of atmospheric moisture transport to Antarctica must also be considered, namely, regional sea ice concentration (SIC)-regulated local evaporative source region variability (Tsukernik and Lynch, 2013; Thomas and Bracegirdle, 2015). Compositing reveals that basin-scale precipitation variability is closely associated with nearby offshore SIC variability: basin-specific high-precipitation years tend to be characterized by statistically significant local decreases in offshore SIC, while lowprecipitation years are characterized by offshore SIC increases (Fig. 6). The broad co-occurrence of low/high upwind SIC with downstream high/low basin-scale precipitation suggests a role for sea-ice-regulated local evaporation source variability in determining basin-scale precipitation variability. However, we argue against this causal relationship because strong increases in annual precipitation minus evaporation $(P-E$, approximately equivalent to moisture flux convergence on annual timescales) that are proximal to 

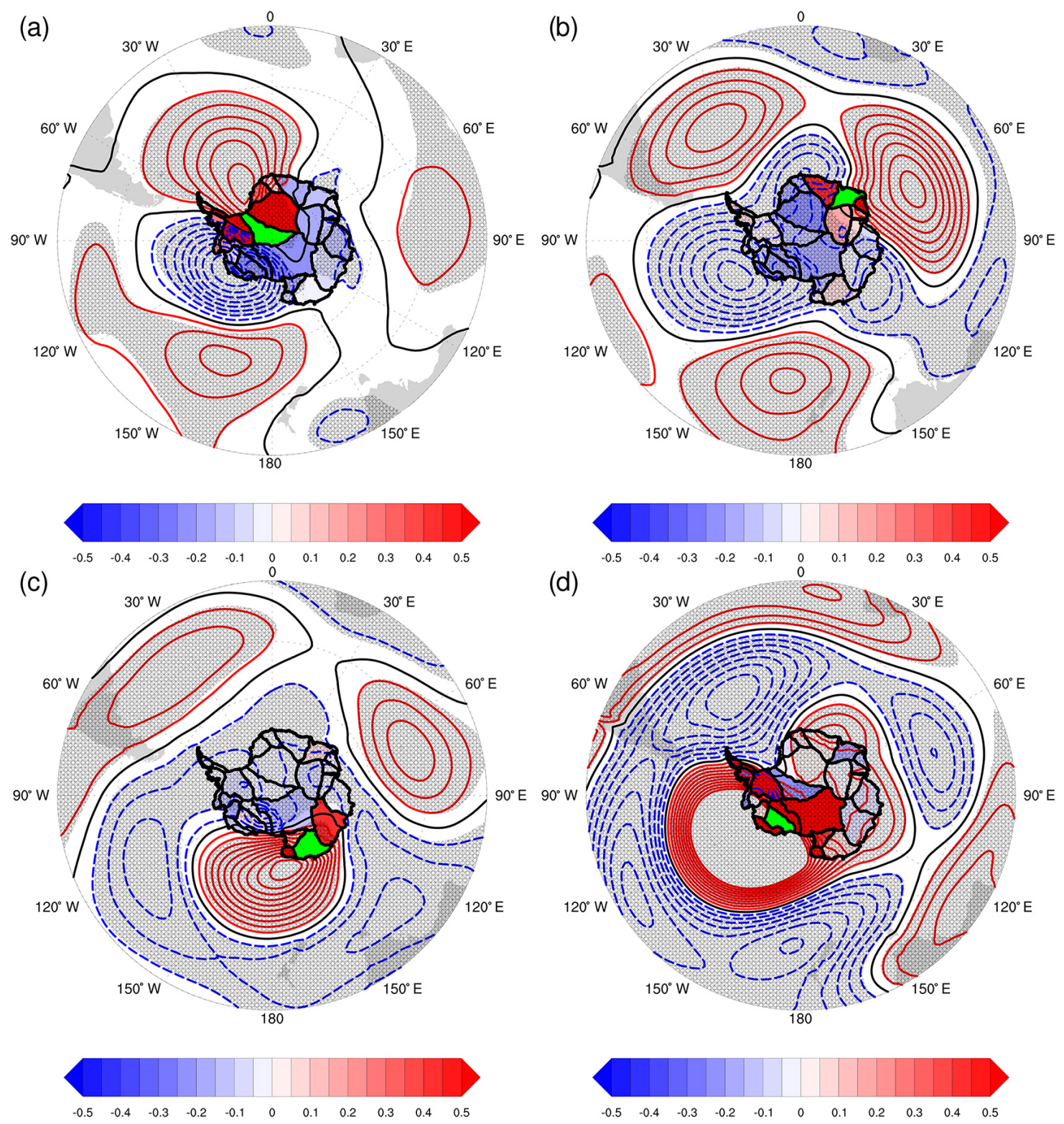

Figure 5. (a-d) Basin-resolved composite climatology Z500 differences (high minus low basin-specific integrated precipitation). Contours at $3 \mathrm{~m}$ geopotential height difference intervals. Positive inter-composite pressure difference colored red, negative inter-composite pressure difference colored blue, to a minimum/maximum of $-30 / 30 \mathrm{~m}$. Zero contour colored black. Stippling: statistically significant inter-composite (95\%) Z500 difference. Basin-specific coloring and basin outlines as in Fig. 4.

the basin upon which compositing was performed are not associated with opposing regions of negative $P-E$ change over nearby sea ice loss regions (Fig. 6). Instead, $P-E$ decreases over these regions are typically weak and in some cases even positive (e.g., Fig. $6 \mathrm{a} / \mathrm{b}$ ), contradicting the pattern that would be expected if SIC-regulated evaporative increases were a dominant factor in locally increased Antarctic basin-scale precipitation: namely, a strong proximal offshore $P-E$ decrease (reflecting increased evaporation) closely associated with the pattern of negative SIC change next to basins experiencing increased precipitation. The argument for a weak dependence of Antarctic precipitation on local SIC state also holds for basins experiencing decreased precipitation, but with reversed tendencies of change. Thus, we conclude that regional sea ice variability is not the primary factor driving basin-scale Antarctic precipitation variability. Rather, both sea ice and Antarctic precipitation variability are both commonly regulated by atmospheric circulation variability, which leads to the appearance of associated (but not causal) spatial variability patterns. This conclusion contradicts speculations by Tsukernik and Lynch (2013); Thomas and Bracegirdle (2015) and Lenaerts et al. (2016) but sup- 


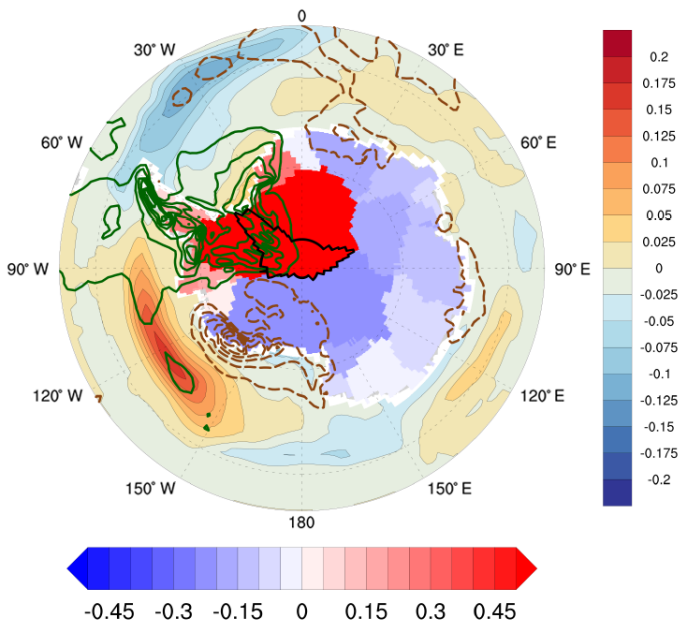

(a)

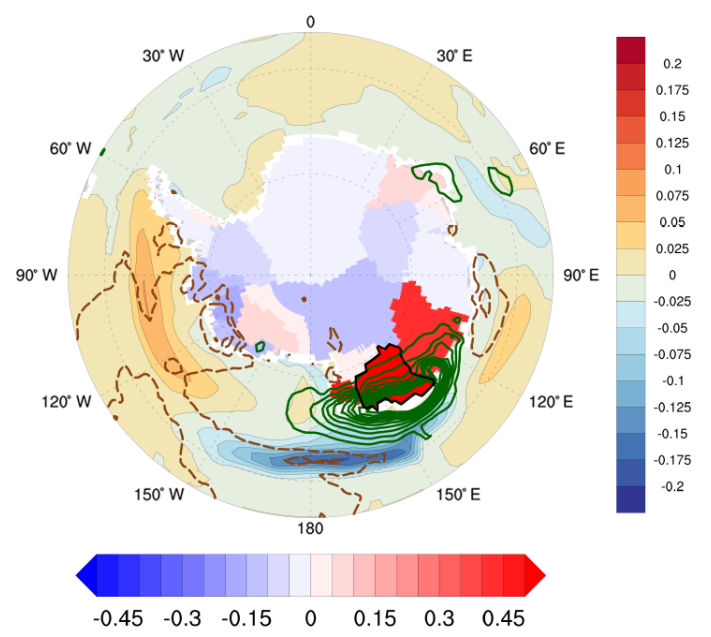

(c)

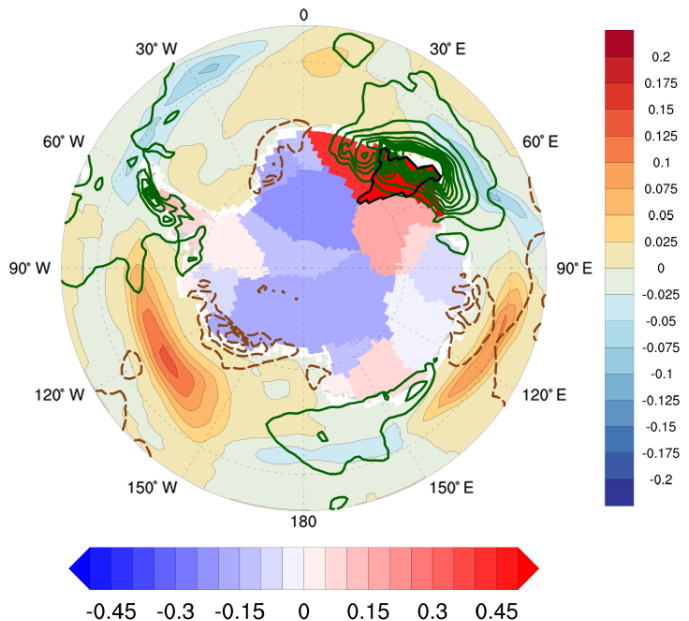

(b)

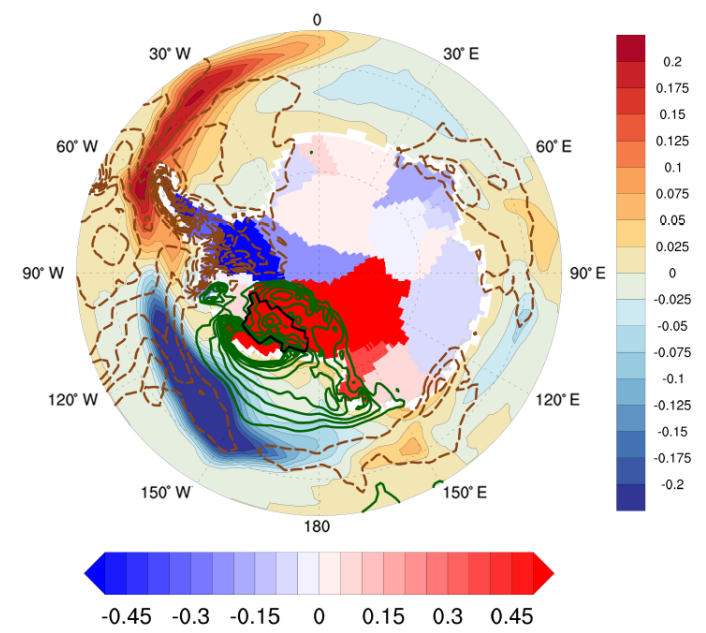

(d)

Figure 6. (a-d) Solid shading over ocean areas: composite sea ice concentration climatology differences (vertical color bar, high minus low basin-specific integrated precipitation). Contour lines: composite $P-E$ climatology differences. Positive inter-composite $P-E$ difference colored green; negative inter-composite $P-E$ difference colored brown. Contours at $1 \mathrm{mg} \mathrm{m}^{-2} \mathrm{~s}^{-1}$ intervals, to a minimum/maximum of $-10 / 10 \mathrm{mg} \mathrm{m}^{-2} \mathrm{~s}^{-1}$. Basin-specific coloring and basin outlines as in Fig. 4 (horizontal color bar).

ports the findings of Genthon et al. (2003) and Singh et al. (2016) and also recent studies exploring sea ice controls on Greenland Ice Sheet climate (Noël et al., 2014; Stroeve et al., 2017).

\subsection{Links to broader patterns of atmospheric variability}

Establishing broad-scale atmospheric circulation variability as the main determinant of both basin-scale precipitation variability and broader inter-basin variability relationships allows for a broader assessment of the role of larger-scale atmospheric circulation variability in controlling these features. Notably, the pattern of atmospheric circulation differences extracted via compositing of basin-scale precipitation clearly reconstructs previously characterized broadscale patterns of variability, highlighting their important impact. 
The CESM-simulated Amundsen-Bellingshausen Sea Low (ABSL) appears to be the most dominant control on individual basin-scale precipitation variability and associated countervailing precipitation patterns. Both the strength and longitudinal location of this low pressure center play a strong role in determining the center and strength of the dipole in countervailing patterns, which is qualitatively consistent with Hosking et al. (2013). Anomalous deepening of this low (represented as negative $\mathrm{Z500}$ values, such as the pattern emerging from the basin 26-based composite; see Supplement) drives increased precipitation in eastern WAIS (due to enhanced onshore maritime flow) and decreased precipitation in western WAIS (due to the increased occurrence of offshore continental flow). Conversely, weakening of the ABSL promotes an opposite response (e.g., as represented by the basin 20 composite). Our findings of a dominant ABSL center of variability and regionally counteracting responses to ABSL change are fully consistent with a reanalysis-based analysis (Genthon et al., 2003) that links this variability to Southern Annular Mode (SAM) and low-latitude Pacific (ENSO) variability.

While ABSL stands out as a dominant center of variability, it also is closely linked and often embedded within broader modes of atmospheric circulation variability that exert additional controls on Antarctic precipitation patterns. Basinscale compositing of several East Antarctic drainage basins, most prominently in the vicinity of Enderby Land and Dronning Maud Land, reconstruct a notable wave-3-like difference pattern in Z500. A relatively more subtle wave-3 pattern also emerges in the basin-scale compositing of several AP basins and also basin 14 (George V Land) hinting at the presence of sensitivity to wave-3 variability at nodes separated by approximately $120^{\circ}$ around Antarctica. This supports a suggestion of a quasi-stationary, temporally variable wave-3 circulation in CESM that impacts Antarctic precipitation along southward-flowing branches of the wave train. The same pattern, at least in the Enderby Land/Dronning Maud Land region, is also associated with coherent remote changes in Z500 and moisture transport, leading to AIS-wide patterns of both muted (but significant) positive and negative inter-basin correlations. The suggestion of a wave-3driven signature on Antarctic precipitation aligns with previous studies that identify the effect of wave- 3 circumpolar circulation non-annularity (e.g., as quantified by the ZW3 index; Raphael, 2004) on meridional moisture transport onto the AIS. However, it contrasts with an assessment that wave3 structures do not contribute significantly to Antarctic precipitation variability (Genthon et al., 2003). This discrepancy perhaps arises because the signature of wave- 3 variability on Antarctic precipitation is swamped in the Antarctic-wide empirical orthogonal function analysis of the latter study, which is dominated by circulation variability in the West Antarctic sector.

For a further set of basins, basin-scale variability appears most linked to local asymmetries in the broad zonal wave-
1 atmospheric circulation. In some cases (e.g., basin 10), basins tend to receive more precipitation primarily as a result of a regional dipole of increased continental and decreased offshore Z500 change, pointing to the presence of a re-occurring asymmetry in circumpolar circulation that is weakly reflected in more remote circulation changes. In other cases (e.g., basin 17, encompassing the South Pole), increased precipitation appears associated with a broader pattern of higher continental and lower maritime Z500 height wave-1 variability that is circumpolar in nature. It is therefore qualitatively similar to the pattern of SAM variability that is highlighted as a strong control on precipitation variability in AIS-wide principal component analysis (Genthon et al., 2003).

\section{Discussion}

In this study we identify the presence of significant dampening and actively countervailing tendencies in CESMsimulated Antarctic annually averaged precipitation variability, the dominant term in the Antarctic surface mass balance. Our finding of countervailing Antarctic variability patterns in CESM agrees with findings of similar patterns in RACMO2 and also in ice-core-based assessments. These similarities give confidence that CESM-simulated patterns of AIS precipitation variability are physically realistic.

Counteracting patterns of basin-integrated CESMsimulated Antarctic precipitation variability are directly linked to - and driven by - variability in broad-scale atmospheric circulation patterns, which impact atmospheric moisture transport pathways. The compositing approach used here isolates the spatial patterns of atmospheric variability that promote this effect, via simultaneous changes to other basins. These basin-specific composite patterns closely resemble known modes of variability that are well known regulators of the Southern Hemisphere's climate. These include, for example, ABSL variability, the SAM and wave-3 non-annularity in zonal atmospheric circulation. In reality, these modes of variability are superimposed in a complex manner that likely includes inter-mode interactions (e.g., Fogt et al., 2011; Hosking et al., 2013). However, it is clear from the initial analysis presented here that each mode has a distinct signature on AIS patterns, and the combined signatures contribute to a dampening of AIS-wide integrated variability. Previous work has identified spatially counteracting impacts of regional atmospheric circulation variability over WAIS that are focused around West Antarctica (Genthon et al., 2003, 2005; Genthon and Cosme, 2003). The findings we present here improve on these important initial analyses, by extending the description of counteracting signals across the entire ice sheet.

In many cases, basin-specific precipitation compositing reveals similar patterns of precipitation variability for nearby basins, including similar distal inter-basin variability rela- 
tionships. This reflects an expected dependence of nearby basins on similar patterns of regional atmospheric variability. However, in some cases, immediately adjacent basins show no statistical correlation despite large moisture transport vector changes (for example, basins 19 and 22, Fig. 4d). In these cases, lack of correlation occurs because the dominant modes of regional atmospheric variability that drive large changes in onshore moisture transport in one basin drive simultaneous changes in moisture advection that are directly across shore from the other, resulting in a change in direction of prevailing moisture transport but insignificant net change in transport magnitude or pathway length. In other cases, adjacent basins exhibit rather significantly anti-correlated variability. The presence of such patterns reflects the location of ice divides coupled to patterns of atmospheric flow anomalies. For example, increased basin 2 precipitation is correlated with decreased precipitation in multiple basins on the other side of East Antarctic ice divides, because the coherent large-scale change in atmospheric circulation that brings flow onshore over basin 2 acts simultaneously to increase continental outflow in these other locations. As a result, many Antarctic ice divides practically mark strong transitions in inter-basin variability phasing. This may be an additional important cause of notably decreased precipitation $\mathrm{CV}$ along these divides (Fig. 2c), as they are influenced by synoptic systems representing counteracting modes of variability from either side of the divide over the course of a surface mass balance year.

Use of inter-basin correlations calculated over the full 1800-year record clearly defines long-term mean inter-basin interannual correlation strengths, but masks multi-decadal to multi-centennial variability in these same relationships. To expose this low-frequency variability, in a similar manner to Genthon and Cosme (2003) we re-calculated inter-basin correlations (here using a 31-year moving window) to define the period over which inter-basin time series were evaluated for correlation strength. Figure 7 demonstrates the time evolution of three inter-basin correlations associated with basin 19 (western West Antarctica), the basin exhibiting both the highest and lowest long-term mean inter-basin correlations: a highly positively correlated time series (between basin 19 and neighboring basin 18); a highly negatively correlated time series (between basin 19 and basin 25, eastern West Antarctica); and in the middle, a weakly correlated time series (between basin 19 and basin 4). All other inter-basin evolving correlation time series are available in the Supplement.

In the positively correlated basin $19 / 18$ case, the 31 -year window correlation coefficient varies by $\sim 0.13$ (peak to trough), with notable variability arising at near-centennial timescales. In comparison the correlation coefficient in the negatively correlated basin $19 / 25$ varies by over 0.5 , presumably reflecting strong centennial-scale variability in ABSL conditions. Finally, the correlation coefficient in the weakly correlated basin 19/4 case varies very strongly ( $\sim 0.8)$. In addition and somewhat remarkably, the correlation time series
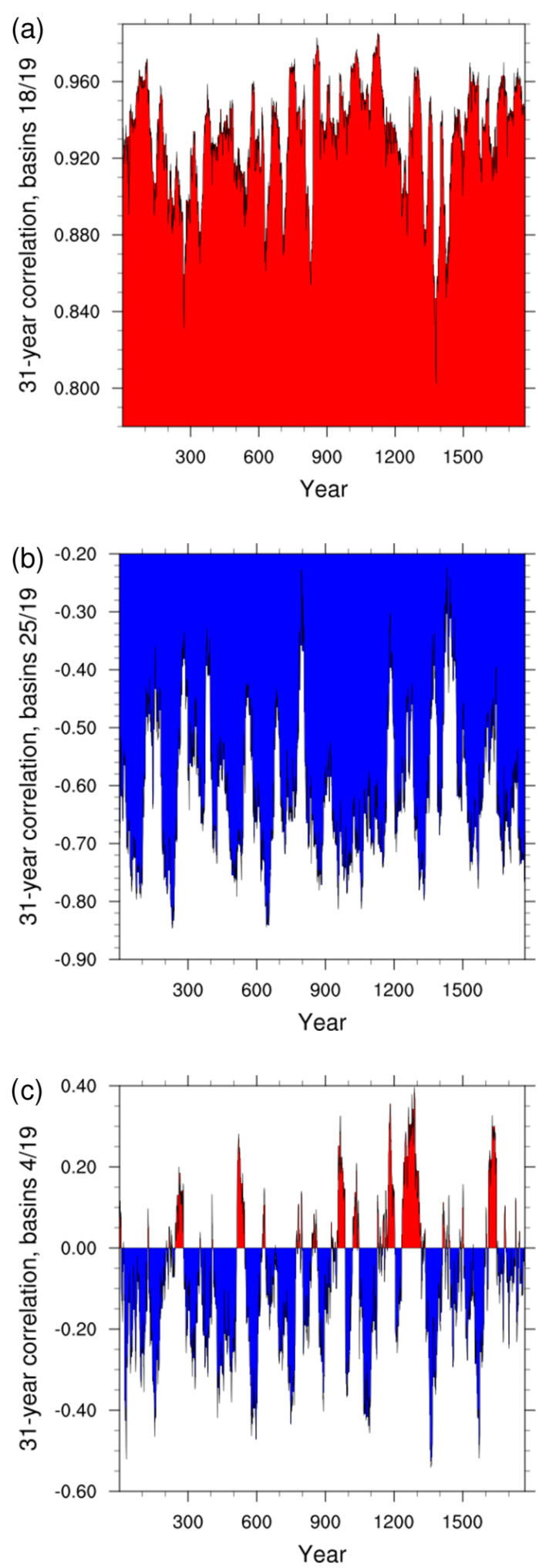

Figure 7. Evolving inter-basin correlations between basin 19 and basins 18, 25 and 4. Correlation time series constructed using a moving 31-year window. Red/blue: positive/negative inter-basin correlation values. 
in this last case exhibits century-scale periods of both negative and positive correlations. This indicates - for this particular inter-basin relationship - the potential for precipitation to vary both in phase and out of phase, with these different regimes able to persist for well over a century.

The presence of significant low-frequency inter-basin precipitation correlations (demonstrated for basin 19, and qualitatively present in other inter-basin correlation time series) likely has implications for interpretation of ice core interrelationships and also modeled and observed precipitation patterns over the recent historical period. In the former case, the finding of significant low-frequency variability about the long-term CESM-simulated mean points to climate models as important tools for mechanistic understanding of poorly understood low-frequency changes in ice core records (e.g., Fudge et al., 2016). In the latter, the simulation of centennialscale variability in inter-basin relationships suggests caution is warranted when interpreting recent Antarctic modeled and observed precipitation changes, since it likely represents an aliased signal of centennial-scale precipitation variability.

We are confident in our CESM-based interpretations of atmospheric circulation controls on inter-basin Antarctic precipitation variability relationships. This confidence arises from corroboration of CESM results with similar RACMO2 results, as well as indications of qualitatively similar precipitation patterns from ice core records (Thomas et al., 2017). However, some fraction of the CESM-simulated structure of inter-basin variability that CESM demonstrates may reflect model bias in both CESM-simulated mean atmospheric circulation and atmospheric circulation variability. For example, Holland et al. (2016) note a general climate model bias towards too-weak modes of non-annular variability in zonal atmospheric flow (e.g., Raphael, 2004) that is shared by CESM. This CESM bias is likely spuriously reducing basinscale counteracting variability, thereby dampening the pattern of counteracting basin-scale variability and potentially explaining the relatively lower magnitude of (anti-) correlation values relative to RACMO2 (Fig. 3). In a similar vein, the ABSL tends to exhibit notable biases in seasonal longitudinal position across a range of climate models (Hosking et al., 2013). However, this dynamical bias is notably minimized in CESM (Hosking et al., 2013; Holland et al., 2016) and is thus unlikely to impact differences between CESM and RACMO2 inter-basin correlations (Fig. 3). Finally, we also note that errors in RACMO2-simulated inter-basin correlation estimates could arise simply from short RACMO2 time series length.

Opposing tendencies in CESM-simulated Antarctic precipitation variability have a strong impact on integrated annually averaged Antarctic snowfall variability, quantitatively reflected in the CV of CESM-simulated AIS-integrated precipitation (0.04) being $\sim 4$ times smaller than basin-scaleaveraged CV (0.17). In the counterfactual case where these dampening and countervailing patterns were entirely absent and the Antarctic continent varied synchronously with a CV of 0.17 , the CESM-simulated AIS integrated variability would increase by $\sim 4$-fold to a $1 \sigma$ standard deviation of $416 \mathrm{Gt} \mathrm{yr}^{-1}$, or approximately $1.2 \mathrm{~mm} \mathrm{yr}^{-1}$ of global mean sea level (GMSL) variability. The additional variability would be comparable in magnitude to 20th century secular sea level rise rates $\left(\sim 1.7 \mathrm{~mm} \mathrm{yr}^{-1}\right.$, Church et al., 2013). Furthermore, it would add notably to GMSL interannual variability, which is dominated by ENSO-driven land water storage changes that generate up to $\sim 5 \mathrm{~mm}$ of sea level anomaly (Llovel et al., 2011). Thus, we argue that atmospherically driven counteracting Antarctic precipitation variability patterns play an important role in moderating GMSL changes by removing a large source of variability from the GMSL budget.

Similarly, we suggest that the presence of dampening/counteracting relationships in patterns of AIS precipitation variability plays an important role in the detection of forced Antarctic mass change signals, because it reduces the effective noise that the signal of forced changes to Antarctic snowfall must overcome to become statistically detectable. For example, Previdi and Polvani (2016) highlight the potential of interannual Antarctic precipitation variability to mask a forced signal of precipitation increases over the 1961-2005 period. Our results suggest that the already-strong masking of forced trends by interannual variability would be even more effective if counteracting patterns in Antarctic precipitation were absent. Similarly, Wouters et al. (2013) highlight the role of Antarctic mass balance variability in obscuring assessments of ice sheet mass loss acceleration over the recent observational time frame. Our results indicate that in the absence of opposing Antarctic precipitation variability patterns, this already significant impediment to assessing integrated Antarctic mass changes would be much greater.

\section{Conclusions}

In this study we analyze climate model output from the Community Earth System Model Large Ensemble preindustrial control simulation to explore patterns of precipitation variability over Antarctica. Most notably, correlation analyses of CESM-simulated precipitation between Antarctic ice drainage basins highlight strong patterns of dampened and opposing basin-integrated precipitation variability. The physical veracity of this finding is supported by very similar behavior in regional modeling, global reanalysis products and ice-core records.

Compositing of climate conditions based on annual precipitation in each basin permits investigation of the broader climate conditions associated with basin-scale integrated precipitation variability. This analysis reconstructs known modes of Southern Hemisphere high-latitude atmospheric circulation variability, confirming these modes as dominant controllers of both basin-scale variability and interbasin countervailing variability patterns. The control arises 
because of variability in atmospheric moisture transport, which strongly regulates Antarctic precipitation patterns and also drives regional sea ice variability. Apparently important sources of variability with respect to regionally countervailing patterns of Antarctic precipitation include the Amundsen/Bellingshausen Sea Low, the zonal wave-3 pattern in circumpolar atmospheric circulation and variability of the Southern Annular Mode. The presence of simulated decadaland centennial-scale variability in inter-basin correlations highlights the potential for low-frequency shifts in Antarctic precipitation variability regimes. Finally, we suggest that dampening of integrated Antarctic precipitation variability due to opposing inter-basin variability patterns has a notable impact on Antarctic mass variability, with potential implications for the detection of ice sheet mass change accelerations, emergence of an anthropogenically forced signal in Antarctic integrated precipitation and global sea level rise changes.

Code and data availability. All NCAR Command Language (NCL Version 6.4.0, 2017, https://doi.org/10.5065/D6WD3XH5) analysis scripts are available at www.github.com/ JeremyFyke/AIS_snowfall_analysis. Directions for obtaining CESM Large Ensemble data are available at www.cesm.ucar.edu/projects/community-projects/LENS/.

\section{The Supplement related to this article is available online} at https://doi.org/10.5194/tc-11-2595-2017-supplement.

Competing interests. The authors declare that they have no conflict of interest.

Acknowledgements. We thank Christophe Genthon, Hansi Singh, Marika Holland and Nicole Jeffrey for useful feedback. Jeremy Fyke and Hailong Wang are supported in this work by the HiLAT project, funded by the US Department of Energy, Office of Science Regional and Global Climate Modeling program. Jan Lenaerts is supported by the Netherlands Science Organization through the Innovational Research Incentives Scheme Veni. We thank the Community Earth System Model Large Ensemble coordinators for making simulation output available.

Edited by: Ross Brown

Reviewed by: two anonymous referees

\section{References}

Boening, C., Lebsock, M., Landerer, F., and Stephens, G.: Snowfalldriven mass change on the East Antarctic ice sheet, Geophys. Res. Lett., 39, L21501, https://doi.org/10.1029/2012GL053316, 2012.
Bromwich, D. H.: Snowfall in high southern latitudes, Rev. Geophys., 26, 149-168, https://doi.org/10.1029/RG026i001p00149, 1988.

Church, J., Clark, P., Cazenave, A., Gregory, J., Jevrejeva, S., Levermann, A., Merrifield, M., Milne, G., Nerem, R., Nunn, P., Payne, A., Pfeffer, W., Stammer, D., and Unnikrishnan, A.: Sea Level Change, book section 13, Cambridge University Press, Cambridge, UK and New York, NY, USA, 1137-1216, https://doi.org/10.1017/CBO9781107415324.026, 2013.

Dee, D. P., Uppala, S. M., Simmons, A. J., Berrisford, P., Poli, P., Kobayashi, S., Andrae, U., Balmaseda, M. A., Balsamo, G., Bauer, P., Bechtold, P., Beljaars, A. C. M., van de Berg, L., Bidlot, J., Bormann, N., Delsol, C., Dragani, R., Fuentes, M., Geer, A. J., Haimberger, L., Healy, S. B., Hersbach, H., Hólm, E. V., Isaksen, L., Kållberg, P., Köhler, M., Matricardi, M., McNally, A. P., Monge-Sanz, B. M., Morcrette, J.-J., Park, B.-K., Peubey, C., de Rosnay, P., Tavolato, C., Thépaut, J.-N., and Vitart, F.: The ERA-Interim reanalysis: configuration and performance of the data assimilation system, Q. J. Roy. Meteor. Soc. 137, 553-597, https://doi.org/10.1002/qj.828, 2011.

Eyring, V., Bony, S., Meehl, G. A., Senior, C. A., Stevens, B., Stouffer, R. J., and Taylor, K. E.: Overview of the Coupled Model Intercomparison Project Phase 6 (CMIP6) experimental design and organization, Geosci. Model Dev., 9, 1937-1958, https://doi.org/10.5194/gmd-9-1937-2016, 2016.

Favier, V., Agosta, C., Parouty, S., Durand, G., Delaygue, G., Gallée, H., Drouet, A.-S., Trouvilliez, A., and Krinner, G.: An updated and quality controlled surface mass balance dataset for Antarctica, The Cryosphere, 7, 583-597, https://doi.org/10.5194/tc-7-583-2013, 2013.

Fogt, R. L., Bromwich, D. H., and Hines, K. M.: Understanding the SAM influence on the South Pacific ENSO teleconnection, Clim. Dynam., 36, 1555-1576, https://doi.org/10.1007/s00382010-0905-0, 2011.

Fretwell, P., Pritchard, H. D., Vaughan, D. G., Bamber, J. L., Barrand, N. E., Bell, R., Bianchi, C., Bingham, R. G., Blankenship, D. D., Casassa, G., Catania, G., Callens, D., Conway, H., Cook, A. J., Corr, H. F. J., Damaske, D., Damm, V., Ferraccioli, F., Forsberg, R., Fujita, S., Gim, Y., Gogineni, P., Griggs, J. A., Hindmarsh, R. C. A., Holmlund, P., Holt, J. W., Jacobel, R. W., Jenkins, A., Jokat, W., Jordan, T., King, E. C., Kohler, J., Krabill, W., Riger-Kusk, M., Langley, K. A., Leitchenkov, G., Leuschen, C., Luyendyk, B. P., Matsuoka, K., Mouginot, J., Nitsche, F. O., Nogi, Y., Nost, O. A., Popov, S. V., Rignot, E., Rippin, D. M., Rivera, A., Roberts, J., Ross, N., Siegert, M. J., Smith, A. M., Steinhage, D., Studinger, M., Sun, B., Tinto, B. K., Welch, B. C., Wilson, D., Young, D. A., Xiangbin, C., and Zirizzotti, A.: Bedmap2: improved ice bed, surface and thickness datasets for Antarctica, The Cryosphere, 7, 375-393, https://doi.org/10.5194/tc-7-375-2013, 2013.

Frezzotti, M., Scarchilli, C., Becagli, S., Proposito, M., and Urbini, S.: A synthesis of the Antarctic surface mass balance during the last $800 \mathrm{yr}$, The Cryosphere, 7, 303-319, https://doi.org/10.5194/tc-7-303-2013, 2013.

Frieler, K., Clark, P. U., He, F., Buizert, C., Reese, R., Ligtenberg, S. R. M., van den Broeke, M. R., Winkelmann, R., and Levermann, A.: Consistent evidence of increasing Antarctic accumulation with warming, Nature Climate Change, 5, 348-352, https://doi.org/10.1038/nclimate2574, 2015. 
Fudge, T. J., Markle, B. R., Cuffey, K. M., Buizert, C., Taylor, K. C., Steig, E. J., Waddington, E. D., Conway, H., and Koutnik, M.: Variable relationship between accumulation and temperature in West Antarctica for the past 31,000 years, Geophys. Res. Lett., 43, 3795-3803, https://doi.org/10.1002/2016GL068356, 2016.

Fyke, J., Carter, L., Mackintosh, A., Weaver, A., and Meissner, K.: Surface melting over ice shelves and ice sheets as assessed from modelled surface air temperatures, J. Climate, 23, 1929-1936, https://doi.org/10.1175/2009JCLI3122.1, 2010.

Genthon, C. and Cosme, E.: Intermittent signature of ENSO in west-Antarctic precipitation, Geophys. Res. Lett., 30, 2081, https://doi.org/10.1029/2003GL018280, 2003.

Genthon, C., Krinner, G., and Sacchettini, M.: Interannual Antarctic tropospheric circulation and precipitation variability, Clim. Dynam., 21, 289-307, https://doi.org/10.1007/s00382-003-0329-1, 2003.

Genthon, C., Kaspari, S., and Mayewski, P. A.: Interannual variability of the surface mass balance of West Antarctica from ITASE cores and ERA40 reanalyses, 1958-2000, Clim. Dynam., 24, 759-770, https://doi.org/10.1007/s00382-005-0019-2, 2005.

Holland, M., Bitz, C., and Hunke, E.: Mechanisms Forcing an Antarctic Dipole in Simulated Sea Ice and Surface Ocean Conditions, J. Climate, 18, 2052-2066, https://doi.org/10.1175/JCLI3396.1, 2005.

Holland, M. M., Landrum, L., Kostov, Y., and Marshall, J.: Sensitivity of Antarctic sea ice to the Southern Annular Mode in coupled climate models, Clim. Dynam., 49, 1-19, https://doi.org/10.1007/s00382-016-3424-9, 2016.

Hosking, J. S., Orr, A., Marshall, G. J., Turner, J., and Phillips, T.: The Influence of the Amundsen-Bellingshausen Seas Low on the Climate of West Antarctica and Its Representation in Coupled Climate Model Simulations, J. Climate, 26, 6633-6648, https://doi.org/10.1175/JCLI-D-12-00813.1, 2013.

Hurrell, J. W., Holland, M., Gent, P., Ghan, S., Kay, J., Kushner, P., Lamarque, J.-F., Large, W., Lawrence, D., Lindsay, K., Lipscomb, W., Long, M., Mahowald, N., Marsh, D., Neale, R., Rasch, P., Vavrus, S., Vertenstein, M., Bader, D., Collins, W., Hack, J., Kiehl, J., and Marshall, S.: The Community Earth System Model: A framework for collaborative research, B. Am. Meteorol. Soc., 94, 1339-1360, https://doi.org/10.1175/BAMS-D12-00121, 2013.

Kay, J. E., Deser, C., Phillips, A., Mai, A., Hannay, C., Strand, G., Arblaster, J. M., Bates, S. C., Danabasoglu, G., Edwards, J., Holland, M., Kushner, P., Lamarque, J.-F., Lawrence, D., Lindsay, K., Middleton, A., Munoz, E., Neale, R., Oleson, K., Polvani, L., and Vertenstein, M.: The Community Earth System Model (CESM) Large Ensemble Project: A Community Resource for Studying Climate Change in the Presence of Internal Climate Variability, B. Am. Meteorol. Soc., 96, 1333-1349, https://doi.org/10.1175/BAMS-D-13-00255.1, 2015.

Lenaerts, J. T. M., Vizcaino, M., Fyke, J., van Kampenhout, L., and van den Broeke, M. R.: Present-day and future Antarctic ice sheet climate and surface mass balance in the Community Earth System Model, Clim. Dynam., 47, 1-15, https://doi.org/10.1007/s00382-015-2907-4, 2016.

Llovel, W., Becker, M., Cazenave, A., Jevrejeva, S., Alkama, R., Decharme, B., Douville, H., Ablain, M., and Beckley, B.: Terrestrial waters and sea level variations on in- terannual time scale, Global Planet. Change, 75, 76-82, https://doi.org/10.1016/j.gloplacha.2010.10.008, 2011.

Martín-Espanõl, A., Zammit-Mangion, A., Clarke, P. J., Flament, T., Helm, V., King, M. A., Luthcke, S. B., Petrie, E., Rémy, F., Schön, N., Wouters, B., and Bamber, J. L.: Spatial and temporal Antarctic Ice Sheet mass trends, glacio-isostatic adjustment, and surface processes from a joint inversion of satellite altimeter, gravity, and GPS data, J. Geophys. Res.-Earth, 121, 182-200, https://doi.org/10.1002/2015JF003550, 2016.

Mémin, A., Flament, T., Alizier, B., Watson, C., and Rémy, F.: Interannual variation of the Antarctic Ice Sheet from a combined analysis of satellite gravimetry and altimetry data, Earth Planet. Sc. Lett., 422, 150-156, https://doi.org/10.1016/j.epsl.2015.03.045, 2015.

Noël, B., Fettweis, X., van de Berg, W. J., van den Broeke, M. R., and Erpicum, M.: Sensitivity of Greenland Ice Sheet surface mass balance to perturbations in sea surface temperature and sea ice cover: a study with the regional climate model MAR, The Cryosphere, 8, 1871-1883, https://doi.org/10.5194/tc-8-18712014, 2014.

Palerme, C., Genthon, C., Claud, C., Kay, J. E., Wood, N. B., and L'Ecuyer, T.: Evaluation of current and projected Antarctic precipitation in CMIP5 models, Clim. Dynam., 48, 1-15, https://doi.org/10.1007/s00382-016-3071-1, 2016.

Previdi, M. and Polvani, L. M.: Anthropogenic impact on Antarctic surface mass balance, currently masked by natural variability, to emerge by mid-century, Environ. Res. Lett., 11, 094001, https://doi.org/10.1088/1748-9326/11/9/094001, 2016.

Raphael, M. N.: A zonal wave 3 index for the Southern Hemisphere, Geophys. Res. Lett., 31, L23212, https://doi.org/10.1029/2004GL020365, 2004.

Santoso, A., England, M. H., and Hirst, A. C.: Circumpolar Deep Water Circulation and Variability in a Coupled Climate Model, J. Phys. Oceanogr., 36, 1523-1552, https://doi.org/10.1175/JPO2930.1, 2006.

Shepherd, A., Ivins, E. R., A, G., Barletta, V. R., Bentley, M. J., Bettadpur, S., Briggs, K. H., Bromwich, D. H., Forsberg, R., Galin, N., Horwath, M., Jacobs, S., Joughin, I., King, M. A., Lenaerts, J. T. M., Li, J., Ligtenberg, S. R. M., Luckman, A., Luthcke, S. B., McMillan, M., Meister, R., Milne, G., Mouginot, J., Muir, A., Nicolas, J. P., Paden, J., Payne, A. J., Pritchard, H., Rignot, E., Rott, H., Sørensen, L. S., Scambos, T. A., Scheuchl, B., Schrama, E. J. O., Smith, B., Sundal, A. V., van Angelen, J. H., van de Berg, W. J., van den Broeke, M. R., Vaughan, D. G., Velicogna, I., Wahr, J., Whitehouse, P. L., Wingham, D. J., Yi, D., Young, D., and Zwally, H. J.: A reconciled estimate of ice-sheet mass balance, Science, 338, 1183-1189, https://doi.org/10.1126/science.1228102, 2012.

Singh, H. A., Bitz, C. M., Nusbaumer, J., and Noone, D. C.: A mathematical framework for analysis of water tracers: Part 1: Development of theory and application to the preindustrial mean state, J. Climate, 8, 991-1013, https://doi.org/10.1002/2016MS000649, 2016.

Sodemann, H. and Stohl, A.: Asymmetries in the moisture origin of Antarctic precipitation, Geophys. Res. Lett., 36, L22803, https://doi.org/10.1029/2009GL040242, 2009.

Stroeve, J. C., Mioduszewski, J. R., Rennermalm, A., Boisvert, L. N., Tedesco, M., and Robinson, D.: Investigating the local-scale 
influence of sea ice on Greenland surface melt, The Cryosphere, 11, 2363-2381, https://doi.org/10.5194/tc-11-2363-2017, 2017.

Thomas, E. R. and Bracegirdle, T. J.: Precipitation pathways for five new ice core sites in Ellsworth Land, West Antarctica, Clim. Dynam., 44, 2067-2078, https://doi.org/10.1007/s00382-014-22136, 2015.

Thomas, E. R., van Wessem, J. M., Roberts, J., Isaksson, E., Schlosser, E., Fudge, T. J., Vallelonga, P., Medley, B., Lenaerts, J., Bertler, N., van den Broeke, M. R., Dixon, D. A., Frezzotti, M., Stenni, B., Curran, M., and Ekaykin, A. A.: Regional Antarctic snow accumulation over the past 1000 years, Clim. Past, 13, 1491-1513, https://doi.org/10.5194/cp-13-1491-2017, 2017.

Trusel, L. D., Frey, K. E., Das, S. B., Karnauskas, K. B., Kuipers Munneke, P., van Meijgaard, E., and van den Broeke, M. R.: Divergent trajectories of Antarctic surface melt under two twenty-first-century climate scenarios, Nat. Geosci., 8, 927-932, https://doi.org/10.1038/ngeo2563, 2015.

Tsukernik, M. and Lynch, A.: Atmospheric Meridional Moisture Flux over the Southern Ocean: A Story of the Amundsen Sea, J. Climate, 26, 8055-8064, https://doi.org/10.1175/JCLI-D-1200381.1, 2013.

Turner, J., Connolley, W. M., Leonard, S., Marshall, G. J., and Vaughan, D. G.: Spatial and temporal variability of net snow accumulation over the Antarctic from ECMWF reanalysis project data, Int. J. Climatol., 19, 697-724, https://doi.org/10.1002/(SICI)10970088(19990615)19:7<697::AID-JOC392>3.0.CO;2-3, 1999. van de Berg, W., van den Broeke, M., Reijmer, C., and van Meijgaard, E.: Reassessment of the Antarctic surface mass balance using calibrated output of a regional atmospheric climate model, J. Geophys. Res., 111, D11104, https://doi.org/10.1029/2005JD006495, 2006.

Van Wessem, J., Reijmer, C., Morlighem, M., Mouginot, J., Rignot, E., Medley, B., Joughin, I., Wouters, B., Depoorter, M., Bamber, J., Lenaerts, J., De Van Berg, W., Van Den Broeke, M., and Van Meijgaard, E.: Improved representation of East Antarctic surface mass balance in a regional atmospheric climate model, J. Glaciol., 60, 761-770, https://doi.org/10.3189/2014JoG14J051, 2014.

Wang, Y., Ding, M., van Wessem, J. M., Schlosser, E., Altnau, S., van den Broeke, M. R., Lenaerts, J. T. M., Thomas, E. R., Isaksson, E., Wang, J., and Sun, W.: A Comparison of Antarctic Ice Sheet Surface Mass Balance from Atmospheric Climate Models and In Situ Observations, J. Climate, 29, 5317-5337, https://doi.org/10.1175/JCLI-D-15-0642.1, 2016.

Wouters, B., Bamber, J., van den Broeke, M., Lenaerts, J., and Sasgen, I.: Limits in detecting acceleration of ice sheet mass loss due to climate variability, Nat. Geosci., 6, 613-616, https://doi.org/10.1038/NGEO1874, 2013.

Zwally, H. J., Giovinetto, M. B., Beckley, M. A., and Saba, J. L.: Antarctic and Greenland drainage systems, GSFC cryospheric sciences laboratory, available at: http://imbie.org/imbie-2016/ drainage-basins/ (last access: 13 November 2017), 2012. 